\title{
Invitro Anti-Bacterial and Anti-0xidative Activity of GlycyrrhizaGlabra L. from North of Golestan Province
}

\author{
Ali Varasteh Moradi (PhD) \\ Department of Chemistry,Islamic \\ Azad University, Gorgan Branch, \\ Gorgan, Iran \\ Sedigheh Zhand (MSc) \\ Department of Chemistry, Islamic \\ Azad University, Gorgan Branch, \\ Gorgan, Iran \\ Corresponding author: Ali \\ VarastehMoradi \\ Email: avmoradi@yahoo.com \\ Tel: +981732132076
}

Adderess: Azad University, Gorgan

Branch, Gorgan, Iran

Received : 07 Oct 2015

Revised: 01 Dec 2015

Accepted: 19 Dec 2015

\section{ABSTRACT}

Background and Objective: Glycyrrhizaglabra L. is one of the most widely used medicinal herbs in Golestan province that is known for its anti-inflammatory, carminative, antiviral, anti-infection and anti-ulcer properties in Iranian traditional medicine. This study aimed to assess the anti-bacterial and anti-oxidative activity of 6. glabrafrom the Golestan province.

Methods: The rip root of the plant was collected in autumn 2013. The ethanolic extract of the plant was prepared by maceration method. The anti-oxidative property of the plant was assessed by total antioxidant capacity (TAC), reducing power (RP) and 1, ldiphenyl-2-picrylhydrazyl (DPPH) radical scavenging capacity assays. The anti-bacterial activity was assessed using agar-well diffusion method and the minimum inhibitory concentration (MIC) assay.

Results: The ethanolic extract of G. glabrahad relatively high anti-oxidative activity with IC50 value of $130 \mu \mathrm{g} / \mathrm{ml}$, especially in the DPPH method. The extract also exhibited high anti-bacterial activity against the following Gram-positive bacteria: Staphylococcus aureus (21.1 $\pm 0.7 \mathrm{~mm})$, Staphylococcus epidermidis $(19.6 \pm 0.2 \mathrm{~mm})$, Bacillus subtilus $(19.3 \pm 0.6 \mathrm{~mm})$, followed by Escherichia coli $(12.1 \pm 0.8 \mathrm{~mm})$, Enterococcus faecalis $(13.2 \pm 0.1 \mathrm{~mm})$ and Kelebsiellapneumoniae $(11.5 \pm 0.4 \mathrm{~mm})$ with MIC values in the range of 31 - $132 \mathrm{mg} \cdot \mathrm{mL}^{-1}$.

Conclusion: According to results, the root extract of G.glabrais a good source of antioxidant compounds with suitable anti-bacterial activity, which can be used as natural anti-infection and anti-inflammatory agent for treatment of many diseases.

KEYWORDS: Anti-Bacterial, Anti-0xidant, Glycyrrhiza, Golestan Province. 


\section{INTRODUCTION}

In recent decades, the increased level of oxidative stress, cell injury and cell death generated during chemotherapy, and antibiotics resistance have been considered the major health problems. Screening of antioxidant and antibacterial activities of natural compounds (polyphenols, terpenoids and flavonoids) present in many wild plants, especially endemic medicinal plants (1-4) has attracted global interest (5-7). Licorice (Glycyrrhizaglabra L.) is a perennial herb with sweet taste in its root that grows wild in subtropical areas of Europe, Middle East and Western Asia. The root extract of the plant and its principal component (glycyrrhizin) have extensive use in food and tea industries, and herbal medicine as strong antiinflammatory, anti-infection, anti-coagulative, anti-allergic, expectorant and especially antiviral agent for treatment of gastric inflammations, gastric ulcer, jaundice and hepatitis $(8,9)$. Several studies have reported that the root extract of G. glabra L. is rich in triterpenes (glycyrrhizin, glycyrrhetinic acid, liquirtic acid) and flavonoids (liquirtin and formononetin) (10). Various chemical constituents including glycyrrhizin, glycyrrhizinic acid, glabridin, glabrene, glabrol, licoflavonol, glycyrol, licoricone, formononetin, glabridin, glabranin isomer andnarigenin have been previously isolated (11). The anti-microbial and anti-viral activity of the G. glabra root extract has been previously reported $(12,13)$; therefore, this study aimed to determine the anti-oxidative and anti-bacterial activity of G. glabra from Gorgan, Golestan Province, Iran.

\section{MATERIAL AND METHODS}

The root of 3-year-old plant was collected in September 2013 from meadows in Northern areas of Gorgan $(35 \mathrm{~m})$, located in Northwest of the Golestan province (latitude of $36^{\circ} 37^{\prime}$ $24^{\prime \prime}$ to $36^{\circ} 34^{\prime} 28^{\prime \prime}$ and longitude of $54^{\circ} 35^{\prime} 26^{\prime \prime}$ to $\left.54^{\circ} 24^{\prime} 32^{\prime \prime}\right)$. The collected roots were kept in silty clay loam soil. A voucher specimen of the plant was identified and deposited at the Herbarium of Research Center of Medicinal plants of Islamic Azad University of Gorgan. The roots were dried in shade, powdered and stored at $4^{\circ} \mathrm{C}$ until invitro testing. One gram of the plant with $100 \mathrm{ml}$ of solvent (methanol $80 \%$ ) was extracted by maceration method. The extracts were filtered with Whatman No.
1 filter paper. The filtrates were evaporated in dry rotary evaporator at $40^{\circ} \mathrm{C}$ and were later stored at $4^{\circ} \mathrm{C} \quad$ (14). 2, $\quad 2^{\prime}$-diphenyl1 picrylhydrazyl (DPPH) was purchased from Sigma Chemical Co. (St., Louis, USA). Other chemical substances and culture plates were purchased from Merck Co. (Germany).

This assay was performed according to Arabshahi-Delouee method. First, the dried extract $(12.5-1000 \mu \mathrm{g})$ in $1 \mathrm{ml}$ of the solvent was mixed with $2.5 \mathrm{ml}$ of phosphate buffer (0.2 M, pH 6.6) and $2.5 \mathrm{ml}$ of potassium ferricyanide $\left(\mathrm{K}_{3} \mathrm{Fe}(\mathrm{CN})_{6} ; 10 \mathrm{gl}^{-1}\right)$. The mixture was incubated at $50^{\circ} \mathrm{C}$ for $30 \mathrm{~min}$. Then, 2.5 $\mathrm{ml}$ of trichloroacetic acid $\left(100 \mathrm{~g} \mathrm{l}^{-1}\right)$ were added and the mixture was centrifuged at 1650 $\mathrm{g}$ for $10 \mathrm{~min}$. Next, $2.5 \mathrm{ml}$ of the supernatant was mixed with $2.5 \mathrm{ml}$ distilled water and 0.5

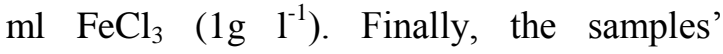
absorbance was measured at $700 \mathrm{~nm}$ (15).

The free radical scavenging activity of the extract was assessed by the method described by a previous study (15). Briefly, $1 \mathrm{ml}$ of 1 mMmethanolic solution of DPPH was mixed with $3 \mathrm{ml}$ of extract solution in methanol (containing 12.5-1000 $\mu \mathrm{g}$ dried extract). The mixture was then vortexed vigorously and left for $30 \mathrm{~min}$ in the dark at room temperature. The absorbance was measured at $517 \mathrm{~nm}$ and DPPH scavenging activity was expressed as percentages relative to controls using the following equation:

$\mathrm{DPPH}$ scavenging activity (\%) = [(Absorbance of control - Absorbance of sample) / Absorbance of control] $\times 100$

This experimental procedure was adapted from Arabshahi-Delouee method, which is based on the reduction of Mo (VI) to Mo (V) by the sample and formation of a green phosphate/Mo (V) complex at acidic $\mathrm{pH}$. An aliquot of $0.1 \mathrm{ml}$ of the sample solution (containing 12.5- $1000 \mu \mathrm{g}$ of dried extract in the corresponding solvent) was combined in a tube with $1 \mathrm{ml}$ of reagent solution $(0.6 \mathrm{M}$ sulphuric acid, $28 \mathrm{mM}$ sodium phosphate, and $4 \mathrm{mM}$ ammonium molybdate). The tube was incubated in a thermal block at $95{ }^{\circ} \mathrm{C}$ for 90 mins. The samples were cooled and their absorbance was measured at $695 \mathrm{~nm}$. A typical blank solution containing $1 \mathrm{ml}$ of the reagent solution and appropriate volume of the solvent was prepared and incubated under the same conditions as the rest of the samples (15). 
The bacterial strains were obtained from the Microbiology Laboratory of Golestan University of Medical Sciences. The ethanolic extract of the roots were individually tested against nine strains of Gram positive and Gram negative bacteria including Shigelladysenteria (PTCC1188), Pseudomonas aeroginosa (PTCC1430),Escherichia coli (PTCC1399), Staphylococcus aureous (PTCC1431), Bacillus cereus (PTCC1015), Salmonella typhimurium(ATCC1596),Staphylocuccusepid ermidis (PTCC1114), Enterococcus faecalis (PTCC1393)

and

Kelebsiellapnumonie(PTCC1291). In the first screening, the extracts were tested against the mentioned bacteria. Minimal inhibitory concentrations (MICs) were determined by the agar serial dilution method at concentrations ranging from 0.93 to $60 \mu \mathrm{g} / \mathrm{mL}$. Two-fold serial dilutions were prepared from the plant extract in molten Mueller Hinton agar (Pronadisa- Madrid) andcooled to $45-50{ }^{\circ} \mathrm{C}$ in a water bath. The plant extract was dispersed in the mixture using dimethyl sulfoxide (DMSO). Then, $0.01 \mathrm{~mL}$ of every bacterial suspension equivalent to a $0.5 \mathrm{McF}$ arland standard $(108 \mathrm{CFU} / \mathrm{mL})$ was inoculated on the agar of each well.
The culture plates were then incubated at 37 ${ }^{\circ} \mathrm{C}$ for 24 hours. The MIC was defined as the lowest concentration at which no visible growth was observed (16). The Mueller Hinton agar containing DMSO without the essential oil was used as negative control, while gentamycin was used as positive control. ANOVA was used to compare the anti-Candida activities of the essential oil and drug. P-value of less than 0.05 was considered statistically significant.

\section{RESULTS}

As shown in Table 1, the results showed that the root extract of G. glabra had suitable antioxidant activity with IC50 value of $130 \pm 1.4 \mu \mathrm{g} / \mathrm{ml}$ in free radical scavenging, especially in the DPPH method. The ethanolic extract of the root had a good potential antimicrobial activity against some Gram-

positivebacteria (Table 2). The maximum antibacterial activity of the extract was observed against Gram positive bacteria including $S$. aureus $(21.1 \pm 0.7 \mathrm{~mm}), \quad S$. epidermidis $(19.6 \pm 0.2 \mathrm{~mm}), \quad B$. subtilus (19.3 $\pm 0.6 \mathrm{~mm})$, followed by $E$. coli $(12.1 \pm 0.8$ $\mathrm{mm})$, E. faecalis $(13.2 \pm 0.1 \mathrm{~mm})$ and $K$. pneumoniae $(11.5 \pm 0.4 \mathrm{~mm})$ with MIC values in the range of $31-132 \mathrm{mg} . \mathrm{mL}^{-1}$.

Table 1- Evaluation oftheantioxidant activity of $G$. glabraL. (collected from Gorgan)using different methods

\begin{tabular}{rccc}
\hline & \multicolumn{3}{c}{ IC50 $(\mu \mathrm{g} / \mathrm{ml})$} \\
\cline { 2 - 4 } Antioxidant activity & Root & BHA & BHT \\
TAC & $510 \pm 1$ & & \\
& & & \\
RP & $799 \pm 1.3$ & $492.6 \pm 0.3$ & $423.6 \pm 0.5$ \\
DPPH & $130 \pm 1.4$ & & \\
\hline
\end{tabular}

Table 2- the anti-bacterial activity of ethanolic extract of G.glabra from Gorgan

\begin{tabular}{cccc}
\hline Bacteria & $\begin{array}{c}\text { Inhibition zone } \\
(\mathrm{mm}) \pm \text { SD }\end{array}$ & MIC $(\mathbf{m g} / \mathbf{m L})$ & Gentamycin \\
\hline . aureus & $21.1 \pm 0.7$ & 31.4 & 20.7 \\
S. epidermidis & $19.6 \pm 0.2$ & 42.1 & 22.3 \\
B. subtilis & & & 16.5 \\
E. faecalis & $19.3 \pm 0.6$ & 49.2 & 9.6 \\
E. coli & $13.2 \pm 0.1$ & 93.2 & 17 \\
P. aeroginosa & $12.1 \pm 0.8$ & 91.6 & 9 \\
K. pneumonia & $11.1 \pm 0.9$ & 110.5 & na \\
S. typhymorium & $11.5 \pm 0.4$ & 124.5 & na \\
S. disentria & $10.2 \pm 0.7$ & 132 & na
\end{tabular}




\section{DISCUSSION}

The results of this study showed that the ethanolic extract of G. glabra root had good anti-bacterial and antioxidant activity in free radical scavenging, especially compared to other species (7). Thus, it can be suggested that terpenoids and polyphenols were the secondary compounds in the G. glabra extract, which might be responsible for the antioxidative, anti-inflammatory, anti-infection and sedative properties of this plant. Several studies reported that the root extract of $G$. glabra L. is rich in triterpenes (glycyrrhizin, glycyrrhetinic acid, liquirtic acid) and flavonoids (liquirtin and formononetin) (10). Many studies have also reported the isolation of various chemical constituents with antioxidative and anti-bacterial properties including glycyrrhizin, glycyrrhizinic acid glabridin, glabrene, glabrol, licoflavonol, glycyrol, licoricone, formononetin, glabridin, glabranin isomer andnarigenin $(11,17)$. In a similar study, it was found that licorice prevents replication of Herpes simplex virus in vitro (12). Some studies indicated that licorice root can be used as a strong anti-inflammatory agent and immune system strengthener for treatment of asthma, immunodeficiency, allergy and liver inflammation, due to its ability to synthesize many antioxidant compounds such as phenolic, terpenoids and flavonoids. These metabolites can also act as antiviral and antiseptic agents that nourishand stimulate the immune system $(18,19)$. The natural antioxidants in G. glabra such as glycyrrhizicacid can reduce the risk of developing infectious and inflammatory diseases and cancer. They can also reduce stomach acid and be used to treat stomach ulcer and disorders of the gastric mucosa (20). It was reported that $S$. aureus, E. coli and $S$. epidermidis are the main causes of infectious furuncles, sores, wounds, nosocomial infections and gasteric ulcer (21). Furthermore, it was shown that the methanolic extract of licorice root have a good antibacterial effect on 12 bacteria, especially against Helicobacter and E. coli, which is in agreement with our findings. Thus, these results prove the medicinal applications of this plant's extract for the treatment of many diseases such as stomach ulcer, disorders of the gastric mucosa and jaundice (22).However, it was reported that Gramnegative bacteria are often more resistant to $G$. glabra (22), which is consistent with the results of the present study. Recently, finding naturally occurring anti-oxidative, antiinflammatory and anti-bacterial agents to replace synthetic drugs for use in food or pharmaceutical industrieshave attracted a lot of attention $(23,24)$.

\section{CONCLUSION}

The results of this study indicate that the root of G. glabra has suitable anti-oxidative and anti-bacterial activity and confirm the traditional uses of this plant in the Golestan province.

\section{AKNOWLEDGEMENTS \\ The authors would like to appreciate honest efforts of respectful personnel of Research Center of Medicinal Plants at Islamic Azad University of Gorgan, as well as Golestan University of Medical Sciences for their cooperation.}

\section{CONFLICT OF INTEREST}

All contributing authors declare no conflicts of interest. 


\section{REFERENCES}

1. Mazandarani M, Borhani G, Fathiazad F Phytochemical analysis, antioxidant activity and ecological requirements of Capparisspinosa $L$. in Golestan and Semnan provinces (North of Iran). Journal of Medicinal Plants and By-products. 2014; 3(1): 21-26.

2. Hammer KA, Carson CF, Riley TV.Antimicrobial activity of essential oils and other plant extracts. Journal of Applied Microbiology. 1999; 86(6): 985-990.

3. ZarghamiMoghaddam P, Zolfaghari MR, Ghaemi EA, Mazandarani M, Mansourian AR, Taheri SA. Negative Performance of Root Extract of OnosmadichroanthumBoiss. on the Burn Wound Healing in an Animal Model. Arch. Clin. Microbial. 2011; 2(5): 3823. doi:10:3823/238.

4. ZarghamiMoghaddam P, Mazandarani M, Zolfaghari M R. Antibacterial and antioxidant activities of root extract of OnosmadichroanthumBoiss. in north of Iran. Afri J Microbiology Research. 2012; 6(8): 1776-1781. DOI: 10.5897/AJMR11.1225.

5. Mazandarani M, Makari S, BajianGh.R, ZarghamiMoghaddam P, Abrodi M. Evaluation of phytochemical and antioxidant activity in different parts of Heracleumgorganicum Rech.in Golestan province of Iran. Iranin J plant physiol. 2011; 2(2): 381386.[Persian]

6. Mazandarani M, Mirdeilami SZ, Pessarakli M. Essential oil composition and antibacterial activity of Achilleamillefolium L. from different regions in North east of Iran. Journal of Medicinal Plants Research. 2013; 7(16): 1063-1069.DOI: 10.5897/JMPR12.961.

7. Sadeghi I, Yousefzadi M, Behmanesh M, Sharifi M. In vitro cytotoxic and antimicrobial activity of essential oil from SaturejaIntermedia. Iranian Red Crescent Medical Journal. 2013; 15(1): 70-4. doi: $10.5812 /$ ircmj. 4989 .

8. Ammosov AS, LitvinenkoVI.Phenolic compounds of the genera GlycyrrhizaL. andMeristotropisFisch. Et Mey.(review).Pharmaceutical Chemistry Journal. 2007; 41: 372-395.

9. Shin YW, Bae EA, Lee B, Lee SH, Kim JA, Kim YS, $\mathrm{Kim} \mathrm{DH}$. Invitro and in vivo antiallergic effects of Glycyrrhizaglabra and its components.PlantaMed. 2007; 73(3): 257-261. PMID:17327992.

10. Farag MA, Porzel A, Wessjohann LA. Comparative metabolite profiling and fingerprinting of medicinal licorice roots using a multiplex approach of GC-MS, LC-MS and ID NMR techniques.Phytochemistry 2012; 76: 60-72.doi: 10.1016/j.phytochem.2011.12.010.

11. Biondi DM, Rocco C, Ruberto G. New dihydrostibene derivatives from the leaves of Glycyrrhizaglabra and evaluation of their antioxidant activity. Journal of Natural Products. 2003; 66(4): 477480.

12. Fiore C, Eisenhut M, Krausse R, Ragazzi E, Pellati $\mathrm{D}$, Armanini D, et al. Antiviral effects of Glycyrrhiza species. Phytother Res. 2008; 22(2):1418.PMID:17886224.
13. Arshad M, Rao A, Ates DA, Erdogrul OT. Antimicrobial activities of various medicinal and commercial plant extracts. Turk J Biol. 2003; 27: 157162.

14. Pourmorad F, Hosseinimehr SJ, Shahabimajd N. Antioxidant activity, phenol and flavonoid contents of some selected Iranian medicinal plants. Afr $\mathrm{J}$ of Biotechnology. 2006; 5(11): 1142-1145.

15. Arabshahi-Delou S, Urooj A. Antioxidant properties of various solvent extracts of mulberry (Morusindica L.) leaves. Food Chem. 2007; 102: 123340.doi:10.1016/j.foodchem.2006.07.013.

16. Ketema T, Kaleab A, Fathy EF, Abdel Nasser S, Bucar B, Franz B. Composition of the essential oils of Saturejaabyssinica ssp. abyssinica and Saturejaparadoxa: Their antimicrobial and radical scavenging activities. Journal of Essential Oil Research. 2007 ; 19

295.DOI:10.1080/10412905.2007.9699285.

17. Jamshidi M, Ahmadi HR, RezazadehSh, Fathi F, Mazanderani M. Study on phenolic antioxidant activity of some selected plants of Mazandaran province. Medic.Plan. 2010; 9(34): 177-183.[Persian].

18. Sahu Y, VaghelaJS.Protective effects of some natural \& synthetic anti-depressants against chronic fatigue induced alterations. JGPT. 2011; 3(2): 21.

19. Rajandeep K, HarpreetK, AjaibS.Glycyrrhizaglabra: A phytopharmacological. IJPSR. 2013; 4(7): 2470-2477. DOI: 10.13040/IJPSR.0975-8232.4(7).2470-77.

20. Fukai T, Marumoa A, Kaitou K, Kanda T, Terada S, Nomura T. Anti-Helicobacter pyloriflavonoids from licorice extract. Life Sciences. 2002; 71(12): 1449-63.

21. Mazandarani M, Osia N, Ghafourian M. Antioxidant activity and ethnopharmacological survey of AchilleabiebersteiniiAfan. in treatment of Dysmenorrhoea in traditional medicine of Golestan Province, Iran. International Journal of Women's Health and Reproduction Sciences. 2015; 3 (2): $107-$ 110.Doi:10.152 96/ijwhr.2015.21.

22. Shapna S, Afroza H, Kaiser H, Kaniz F, Sumon R.Anti-microbial, cytotoxic and antioxidant activity of methanolic extract of Glycyrrhizaglabra. AgricBiol J N $\begin{array}{llll}\text { Am. } & 2010 ; & 1(5): & 957-96\end{array}$ doi:10.5251/abjna.2010.1.5.957.960.

23.Zheng W, WangSY.Antioxidant Activity and Phenolic Compounds in Selected Herbs.JAgric Food Chem. 2001; 49 (11): 5165-5170. PMID:11714298.

24. Kessler M, Ubeaud G, Jung L. Anti and pro-oxidant activity of rutin and quercetin derivatives. J Pharmacy and Pharmacology. 2003, 55(1): 131-142. 